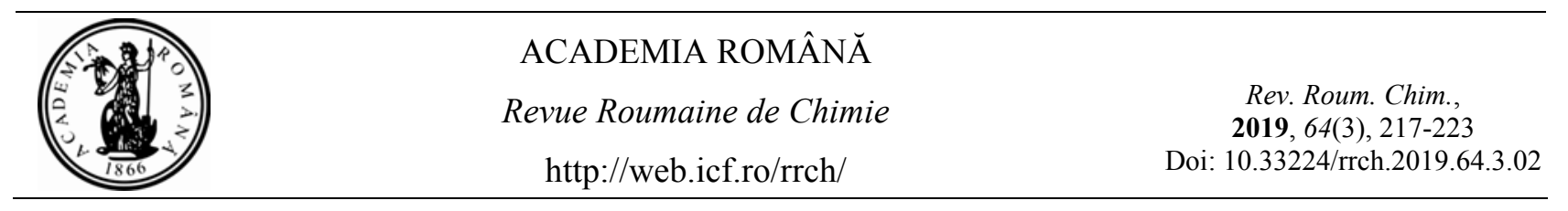

\title{
ANTIOXIDANT CAPACITY MEASUREMENT OF ANILINE-PYRROLE COPOLYMER BY FRAP ASSAY
}

\author{
Sara AMANZADEH-SALOUT, ${ }^{*}$ Seyed Zoheir SAMIEI-KASHI and Ali PARSA
}

Young Researchers and Elite Club, Yadegar-e- Imam Khomeini (RAH) Shahr-e-Rey Branch, Islamic Azad University, Tehran, Iran

Received October 11, 2018

Based on wide variety of methods in evaluation of antioxidant activity, Ferric Reducing Antioxidant Power (FRAP) assay is another simple test to assess the total antioxidant power of aniline-pyrrole copolymer poly[Anico-Py] in this study. Initially, the electrosynthesis of poly[Ani-co-Py] was done by cyclic voltammetry (CV) method in acidic medium $\left(\mathrm{H}_{3} \mathrm{PO}_{4}\right)$ containing different molar fraction of calcium chloride $\left(\mathrm{CaCl}_{2}\right)$ and paratoluene sulfonic acid (PTSA). After characterization and structural analysis of modified electrodes by SEM, FTIR and UV-vis spectroscopy, the antioxidant activity was proven. In the study of antioxidant power, the operation of FRAP assay at low $\mathrm{pH}$ depends on the reduction of ferric tripyridyltriazine $\left[\mathrm{Fe}^{3+}-\mathrm{TPTZ}\right]$ complex to the intensely blue colored ferrous tripyridyltriazine $\left[\mathrm{Fe}^{2+}-\mathrm{TPTZ}\right]$ by antioxidants. This reduction is monitored by measuring the change in absorption maximum at $593 \mathrm{~nm}$. Ultimately, the obvious changes in both color and absorption development at $593 \mathrm{~nm}$ confirmed the antioxidant capability of aniline-pyrrole electrocopolymerized electrodes.

\section{INTRODUCTION}

Several assays have been used to estimate antioxidant capacity including 2,2-azinobis (3ethyl-benzothiazoline-6-sulfonic acid) (ABTS), 2,2-diphenyl-1-picrylhydrazyl (DPPH), the oxygen radical absorption capacity (ORAC) and ferric reducing antioxidant power (FRAP). ${ }^{1-3}$ The Ferric Reducing Antioxidant Power (FRAP) assay is a simple test using reductant (antioxidant) in a redox reaction with oxidant and combined with colorimetric method. The method described determines the ferric reducing ability in a complex form of ferric tripyridyltriazine $\left[\mathrm{Fe}^{3+}-\mathrm{TPTZ}\right]$ when reduced to ferrous tripyridyltriazine $\left[\mathrm{Fe}^{2+}-\mathrm{TPTZ}\right]$ at low $\mathrm{pH}$. Development of intense blue color at $\lambda_{\max }$ 593 shows the presence of antioxidant. ${ }^{4-6}$

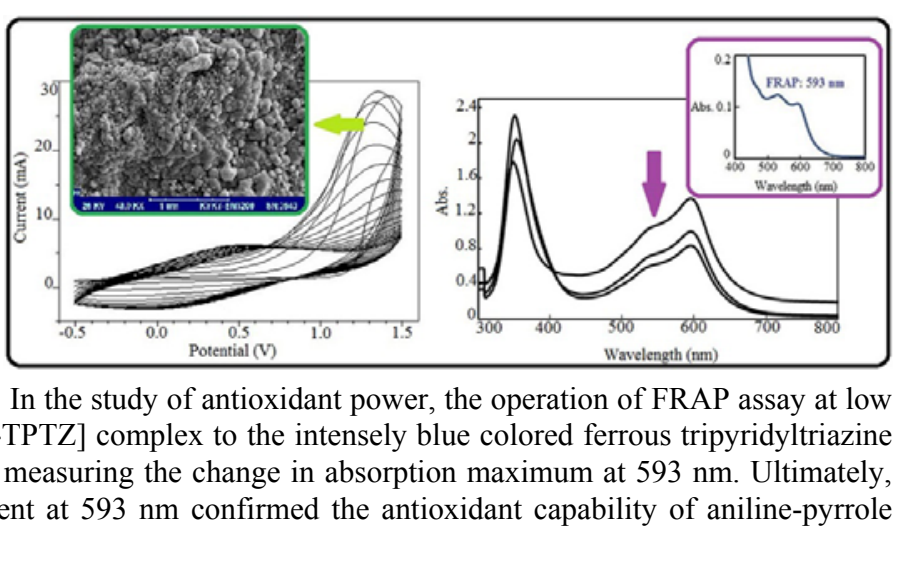

*Corresponding author: sara.amanzadeh@gmail.com, Tel.: +989122281549

The significance of oxidation in the body is widely known. It is evident that the oxidative metabolism is needed for the cells survival to protect the key cell component by preventing the deleterious effects of free radicals. ${ }^{2,7}$ In our daily life, we use natural antioxidant in fruits and vegetables that have defensive effect with lower risk of cancers and cardiovascular diseases. Antioxidants are divided in three main groups of vitamins, phenolics and carotenoids. Hydrophilic antioxidants consist of ascorbic acid and phenolics, while lipophilic antioxidants consist of carotenoids. ${ }^{1}$ Examples of phenolic antioxidants include polymers such as; polyaniline, polypyrrole and other polyphenols that have antioxidant properties.

The aim of this research was to evaluate the antioxidant activity of electrosynthesized aniline 
pyrrole copolymer. The modified electrodes were synthesized through cyclic voltammetry method in $\mathrm{H}_{3} \mathrm{PO}_{4}$ medium containing $\mathrm{CaCl}_{2}$ and PTSA as supporting electrolyte. The FTIR, UV-vis spectroscopy and SEM were used for characterization and structural analysis. Finally, the measurement of antioxidant capacity was studied by FRAP assay.

\section{RESULTS AND DISSCUSION}

\section{Aniline-pyrrole Electrocopolymerization}

The copolymer of aniline and pyrrole have been prepared by the oxidation of $50 \mathrm{mM}$ monomers mixture. ${ }^{8}$ Figure 1a to $1 \mathrm{c}$ illustrates the growth of copolymer on graphite composite in acidic medium containing both inorganic and organic supporting electrolyte. The applied potential was varied from -0.5 to $+1.5 \mathrm{~V}$ versus $\mathrm{Ag} / \mathrm{AgCl}$ at a scan rate of $100 \mathrm{mV} / \mathrm{s}^{-1}$ and up to 20 cycles.

It can be seen from the voltammogram in Figure 1a that a redox couple peak appears during the electrosynthesis of Ani-Py copolymer in the presence of $\mathrm{CaCl}_{2}$ denoted $\mathrm{O}^{*} / \mathrm{R}^{*}$ peak while other $\mathrm{CVs}$ in Figure $1 \mathrm{~b}$ to $1 \mathrm{c}$ demonstrates that as the molar ratios of PTSA increase, the denoted $\mathrm{O}^{*} / \mathrm{R}^{*}$ peak disappears. ${ }^{9}$ Moreover, in this study, the presence of supporting electrolytes in the electrosynthesis of copolymers have an important role on their electrical conductivity. $\mathrm{CaCl}_{2}$ as an inorganic supporting electrolyte helps to increase the dielectric constant of solution as a result the acidity of the medium is increased then the poly[Ani-co-Py] electrosynthesized in the presence of $\mathrm{CaCl}_{2}$ have higher conductivity and as the molar ratios of PTSA increase, the conductivity of poly[Ani-co-Py] decreases.

This implies that the copolymer electrosynthesized in the presence of PTSA is less conductive. ${ }^{3,9-11}$

\section{Structural Analysis of Ani-Py Copolymer}

The FTIR spectra of Ani-Py copolymer is divided into three groups in accordance with medium containing different molar fractions of supporting electrolyte (Figure 2a to 2c) including: $1.0 \mathrm{mM} \mathrm{CaCl}_{2}, 5: 5 \mathrm{mM} \mathrm{CaCl}_{2}$ and PTSA and $1.0 \mathrm{mM}$ PTSA. The similarity between the three curves with little differences in the width and intensity of peaks are evident and these inevitable differences in the position of absorption bands can pertain to the bonding between aniline and pyrrole in electrosynthesis and the presence of various supporting electrolytes. The supporting electrolytes have straight impact towards the formation of polymer chains then the polymer chains might be change by using different types of supporting electrolytes. ${ }^{12}$ To a great extent, when the mixture of two distinct monomers are polymerized, the IR spectrum of the product is close to the spectrum of the respective homopolymer. The FTIR spectra of copolymers prepared from the mixture of both monomers are presented in Figure 2. Figure 2a to 2c demonstrates the FTIR spectra of poly[Ani-co$\mathrm{Py}]$ and the characteristics peaks of both Ani and Py confirm the formation of Ani-Py copolymers. The existence of PAni which appeared at 1277 and $1397 \mathrm{~cm}^{-1}$ while the $\mathrm{C}=\mathrm{C}$ stretching band at 1633 $\mathrm{cm}^{-1}$ and $\mathrm{C}-\mathrm{H}$ vibrational band at $1104 \mathrm{~cm}^{-1}$ are the characteristics peaks of PPy. The peak at $993 \mathrm{~cm}^{-1}$ corresponds to C-H out-of-plane deformation of the pyrrole units. ${ }^{13-17}$ The absorption band between 1000 to $1397 \mathrm{~cm}^{-1}$ attributed to the $\mathrm{C}-\mathrm{N}$ bonds, next it has been reported that the absorption band from 3407 to $3470 \mathrm{~cm}^{-1}$ contributed to aromatic $\mathrm{N}-\mathrm{H}$ bonds stretching vibrations in PPy. ${ }^{12,17,18}$ Moreover, the comparison of FTIR spectra indicates that the existence of the characteristics band of PPy in copolymer prepared in the presence of $\mathrm{CaCl}_{2}$ is less prominent than PAni while it would be vice versa as the molar fraction of PTSA increases in the copolymer. ${ }^{9}$

Figure 3 shows the UV-Vis spectra of copolymer with equimolar mixture of both Ani and Py. The poly[Ani-co-Py] is prepared in the presence of different molar ratios of $\mathrm{CaCl}_{2}$ and PTSA supporting electrolyte. As can be clearly seen, the poly[Ani-co-Py] exhibits approximately monotonous absorption throughout the visible region and base on recent work, this experimental UV-vis spectrum is in close agreement with latest reported results and the single maximum absorption peak at $365 \mathrm{~nm}$ might be due to the valence electron transition to the conduction band. ${ }^{8,19,20}$ Moreover, it is evident that as the molar ratios of the PTSA supporting electrolyte increase, the absorption of poly[Ani-co-Py] decreases and this might be due to the low conductivity of electrosynthesized copolymer in the presence of pure molar fraction of PTSA. 
Regarding the structural analysis and characterization study of electrosynthesized copolymer in the presence of $\mathrm{CaCl}_{2}$ and PTSA supporting electrolyte, SEM was used to investigate surface morphology. Figure 4 depicts the morphology of poly[Ani-co-Py] samples with both mixtures of $\mathrm{CaCl}_{2}$ and PTSA acting as supporting electrolytes from different surface area at various magnifications. It shows the cluster grape structure of poly[Ani-co-Py]; in addition, the SEM of poly[Ani-co-Py] confirmed the electrosynthesis of copolymer in nano scale.
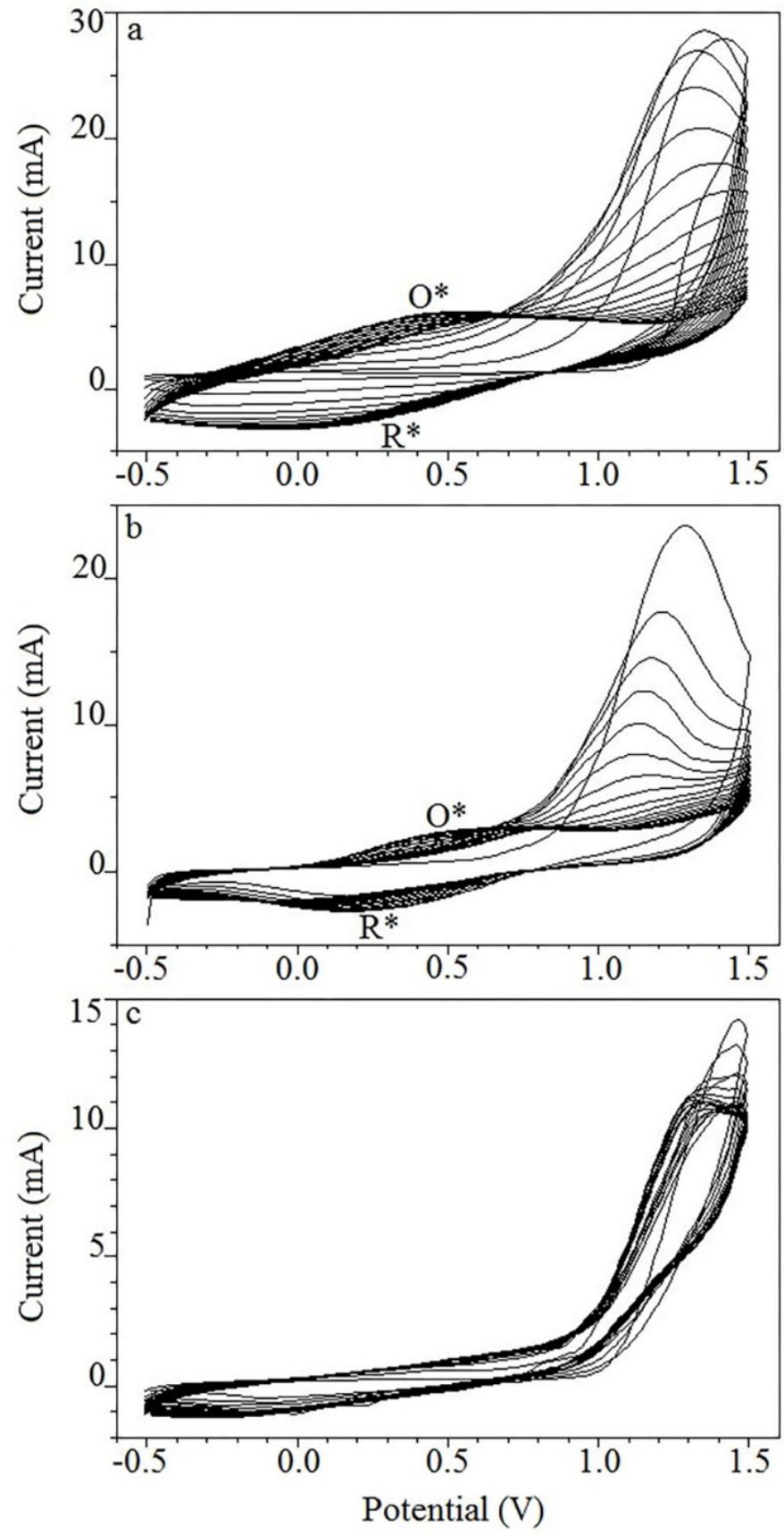

Fig. $1-\mathrm{CVs}$ of $50 \mathrm{mM}$ Ani and $50 \mathrm{mM}$ Py in $1 \mathrm{M} \mathrm{H}_{3} \mathrm{PO}_{4}$ containing $1 \mathrm{M} \mathrm{CaCl}_{2}$ and $0.2 \mathrm{M}$ PTSA at various molar fractions: (a) $1.0: 0.0$, (b) $0.5: 0.5$, (c) $0.0: 1.0$. The applied potential, $\mathrm{E}_{\text {app }}-0.5$ and $+1.5 \mathrm{~V}$ ( vs. $\mathrm{Ag} / \mathrm{AgCl})$, scan rate is $100 \mathrm{mVs}^{-1}$ and scanning up to 20 cycles. 

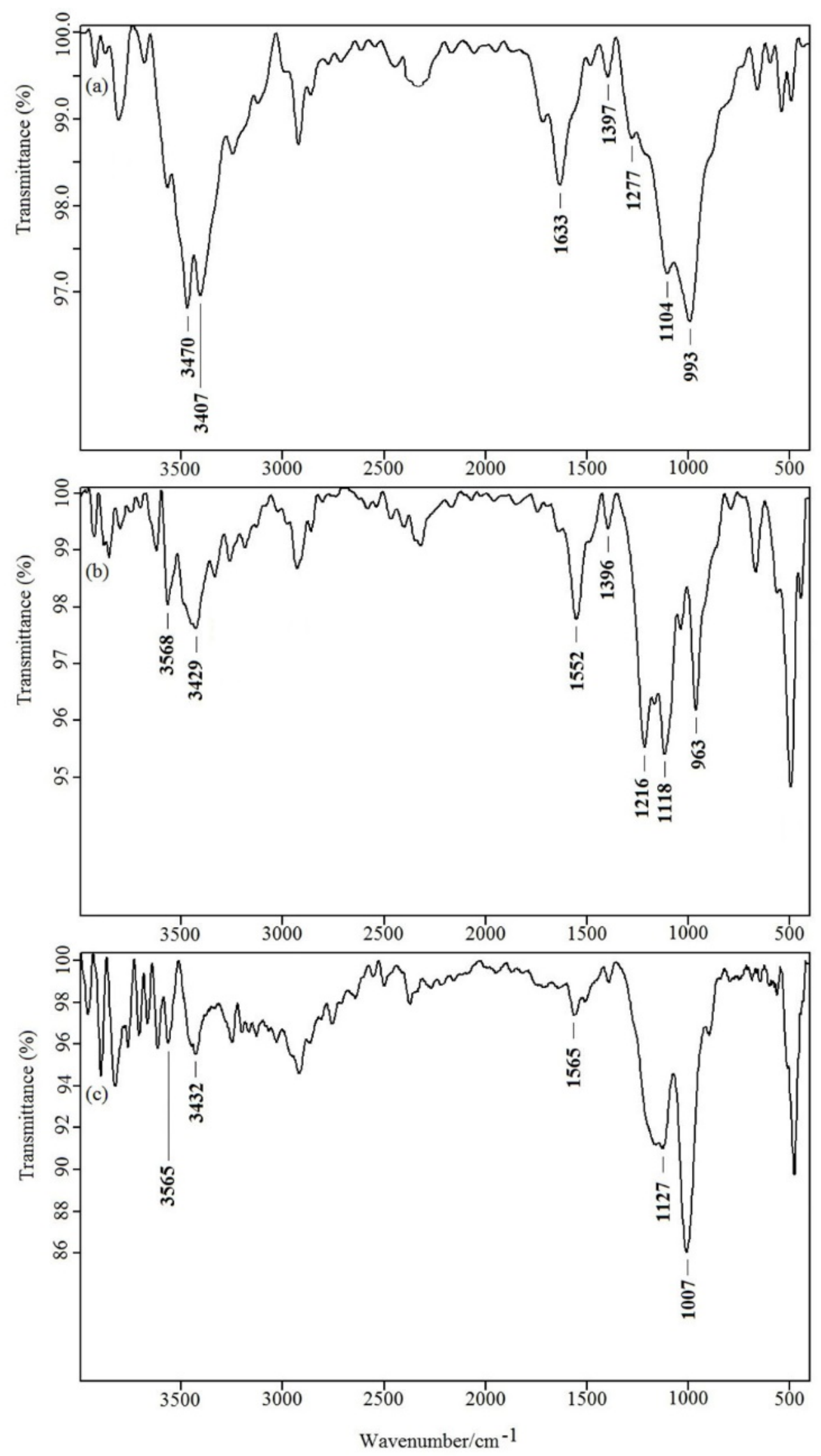

Fig. 2 - Baseline corrected FTIR spectra of poly[Ani-co-Py] in $1 \mathrm{M} \mathrm{H}_{3} \mathrm{PO}_{4}$ containing $1 \mathrm{M} \mathrm{CaCl}_{2}$ and 0.2 M PTSA at various molar fractions: (a) 1.0:0.0, (b) 0.5:0.5, (c) 0.0:1.0. 


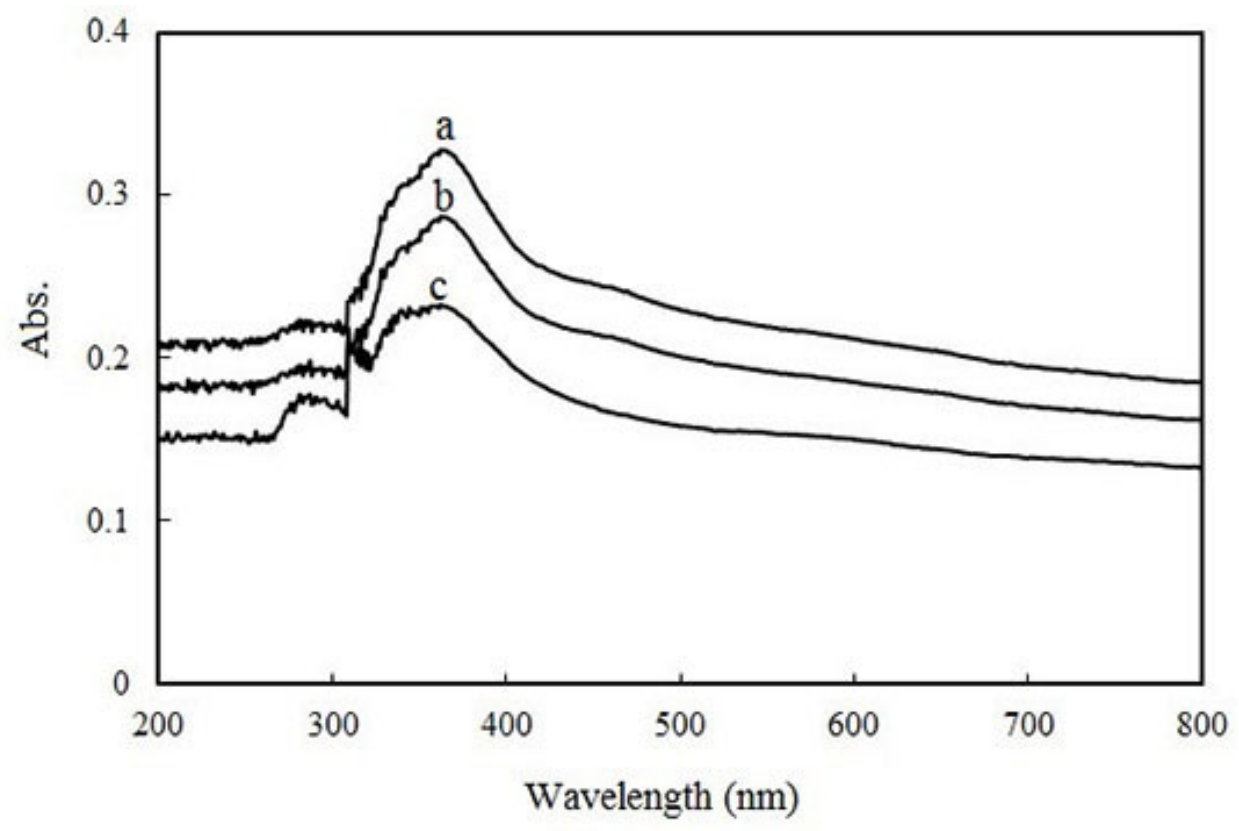

Fig. 3 - UV-vis spectra of poly[Ani-co-Py] in $1 \mathrm{M} \mathrm{H}_{3} \mathrm{PO}_{4}$ containing $1 \mathrm{M} \mathrm{CaCl}_{2}$ and $0.2 \mathrm{M}$ PTSA at various molar fractions: (a) 1.0:0.0, (b) 0.5:0.5, (c) 0.0:1.0.
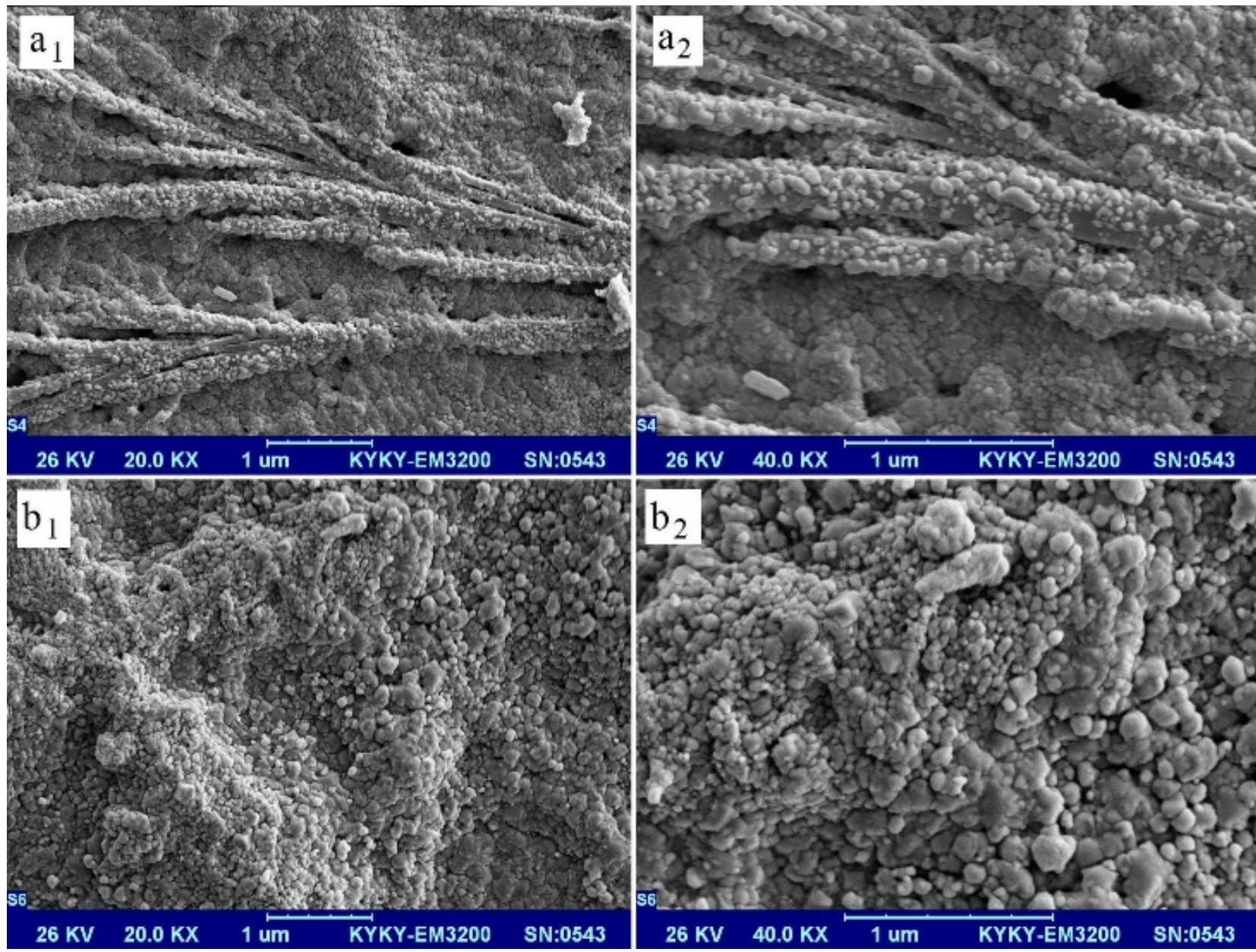

Fig. 4 - SEM of poly[Ani-co-Py] synthesized electrochemically in acidic medium including $1 \mathrm{M} \mathrm{CaCl}_{2}$ and $0.2 \mathrm{M}$ PTSA on composite $2 \mathrm{~B}$ pencil graphite; $\left(\mathrm{a}_{1}: \mathrm{b}_{1}\right)$ at different areas, $\left(\mathrm{a}_{2}: \mathrm{b}_{2}\right)$ SEM recorded at respective higher magnifications. 


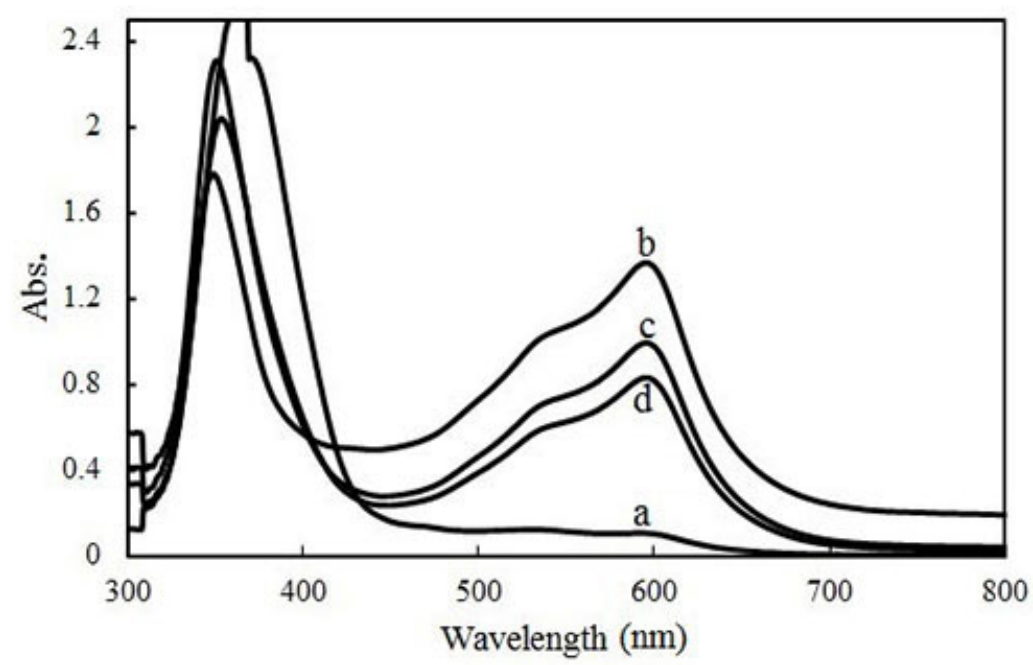

Fig. 5 - UV-vis spectra of FRAP, (a) The absorbance of FRAP (at $593 \mathrm{~nm}$ ) after $30 \mathrm{~min}$ exposure to electrosynthesized poly[Ani-co-Py] with different molar ratios of $\mathrm{CaCl}_{2}$ to PTSA: (b) 1.0:0.0, (c) 0.5:0.5, (d) 0.0:1.0.

\section{Antioxidant Capacity Measurement of poly[Ani-co-Py]}

The evaluation of antioxidant activity of poly[Ani-co-Py] was investigated by FRAP assay. The response of UV-vis spectrum in order to study the copolymer antioxidant capacity indicates that the intensity of FRAP maximum absorption at $593 \mathrm{~nm}$ increases and this due to the role of poly[Ani-co-Py] as reductant to reduce the oxidant (Fig. 5). ${ }^{21-23}$ Furthermore, in the mixture of ferric tripyridyltriazine complex $\left[\mathrm{Fe}^{3+}-\mathrm{TPTZ}\right]$ with copolymer, $\left[\mathrm{Fe}^{3+}-\mathrm{TPTZ}\right]$ is reduced to ferrous tripyridyltriazine $\left[\mathrm{Fe}^{2+}-\mathrm{TPTZ}\right]$ via poly[Ani-co-Py] and then the intense blue color causes the maximum absorption to increase at $593 \mathrm{~nm}$ and the antioxidant properties of poly[Ani-co-Py] is confirmed. In addition, according to the previous description, poly[Ani-co-Py] electrosynthesized in the presence of three different molar fractions of $\mathrm{CaCl}_{2}$ and PTSA supporting electrolytes and in antioxidant activity study shows that as the molar ratios of PTSA increase in the synthesis of copolymer, the intensity of absorption at $593 \mathrm{~nm}$ decreases ultimately. This shows that the antioxidant capacity of Ani-Py electrosynthesized copolymer in the presence of $\mathrm{CaCl}_{2}$ supporting electrolyte is higher than other copolymers electrosynthesized in the presence of PTSA (Figure $5 \mathrm{~b}$ to $5 \mathrm{c}$ ).

\section{EXPERIMENTAL}

\section{Materials}

Pyrrole (Py) (Merck, Germany) was vacuum distilled before use. Aniline (Ani) (Sigma Chemicals, USA) was distilled under nitrogen atmosphere at reduced pressure. The resulting colorless liquid was kept in the dark at $5{ }^{\circ} \mathrm{C}$. Phosphoric acid $\left(\mathrm{H}_{3} \mathrm{PO}_{4}\right)$, Hydrochloric acid $(\mathrm{HCl})$, Acetic acid $\left(\mathrm{C}_{2} \mathrm{H}_{4} \mathrm{O}_{2}\right)$, Sodium acetate trihydrate $\left(\mathrm{C}_{2} \mathrm{H}_{3} \mathrm{Na}_{2} \cdot 3 \mathrm{H}_{2} \mathrm{O}\right)$, paratoluenesulfonic acid (PTSA), Calcium chloride $\left(\mathrm{CaCl}_{2}\right) ; N, N$-dimethylformamide (DMF) and methanol (MeOH) (BDH Chemicals, UK) were used as received. 2,4,6-tris(2-pryidyl)-striazine (TPTZ) was purchased from (Sigma Chemicals, USA) and Iron(III) chloride hexahydrate $\left(\mathrm{FeCl}_{3} \cdot 6 \mathrm{H}_{2} \mathrm{O}\right)$ was obtained from (Shanghai No.1Reagent Factory, China). All aqueous solutions were freshly prepared using ultra-pure water from Milli-Q plus (Millipore Corp., USA).

\section{Equipment}

A custom-made three-neck cell was used throughout the electrochemical synthesis and characterization of copolymer by CompactStat potentiostat (Ivium Technologies, Netherlands), the composite 2B pencil graphite (Staedtler Lumograph, Germany) was used as working and counter electrodes against pseudo $\mathrm{Ag} / \mathrm{AgCl}$ reference electrode. The structural characterization was carried out with FTIR spectrophotometer System 2000 (Perkin Elmer, USA) and the antioxidant investigation was determined by UV-visible spectrophotometer V-500 (JASCO, Japan). The morphology of the copolymer was inspected using SEM equipped with an Oxford INCA 400 (Bucks. U.K.).

\section{Procedure}

\section{Electrosynthesis of Poly[Ani-co-Py]}

The electrosynthesis carried out at potential between -0.5 and $+1.5 \mathrm{~V}$ vs. $\mathrm{Ag} / \mathrm{AgCl}$, scan rate $100 \mathrm{mVs}^{-1}$, under OFN atmosphere and at $25 \pm 2{ }^{\circ} \mathrm{C}$. The cyclic voltammetry method performed on the surface of composite $2 \mathrm{~B}$ pencil graphite in $10 \mathrm{~mL}$ solution containing $50 \mathrm{mM}$ aniline and $50 \mathrm{mM}$ Pyrrole with mixture of $1 \mathrm{M} \mathrm{H}_{3} \mathrm{PO}_{4}$ (medium), $1 \mathrm{M} \mathrm{CaCl}_{2}$ and $1 \mathrm{M}$ PTSA as supporting electrolyte.

\section{FRAP Assay}

The FRAP assay was done according to the Benzie and Strain (1996) with some modifications ${ }^{4}$. The stock solutions included $300 \mathrm{mM}$ acetate buffer at $\mathrm{pH} 3.6,10 \mathrm{mM}$ TPTZ solution in $40 \mathrm{mM} \mathrm{HCl}$ and $20 \mathrm{mM} \mathrm{FeCl} 3.3 \mathrm{H}_{2} \mathrm{O}$ solution. The 
fresh working solution was prepared by mixing $25 \mathrm{~mL}$ acetate buffer, $2.5 \mathrm{~mL}$ TPTZ solution and $2.5 \mathrm{~mL} \mathrm{FeCl}_{3} \cdot 6 \mathrm{H}_{2} \mathrm{O}$ solution and then warmed at $37{ }^{\circ} \mathrm{C}$ before using. $1 \mathrm{mg}$ of poly[Ani-coPy] were allowed to react with $4 \mathrm{~mL}$ of the FRAP solution for $30 \mathrm{~min}$ in the dark condition. Reading the colored solution (ferrous tripyridyltriazine complex) were then taken at $593 \mathrm{~nm}^{1}$.

\section{CONCLUSION}

In summary, it has been shown that the poly[Ani-co-Py] is electrosynthesized using cyclic voltammetry method in acidic medium containing different molar fractions of $\mathrm{CaCl}_{2}$ and PTSA supporting electrolyte. Then after precise consideration and confirmation of structural analysis and characterization, the antioxidant activity investigation was proven via FRAP assay. The UV-vis spectra demonstrate the antioxidant properties of copolymer whenever the intense blue colored is developed at the absorption maximum of $593 \mathrm{~nm}$ by reduction of $\left[\mathrm{Fe}^{3+}\right.$-TPTZ] complex to $\left[\mathrm{Fe}^{2+}-\mathrm{TPTZ}\right]$. Another striking point is attributed to the effect of different molar ratios in the synthesis of copolymer on antioxidant power, it shows that the antioxidant capacity of copolymer in the presence of $\mathrm{CaCl}_{2}$ is more than copolymers electrosynthesized in the presence of PTSA and this confirmed why the maximum absorption at $593 \mathrm{~nm}$ decreases by increasing the molar fraction of PTSA supporting electrolyte.

Acknowledgment: The authors are grateful to the Young Researchers and Elite Club, Yadegar-e- Imam Khomeini (RAH) Shahr-e-Rey Branch, Islamic Azad University for valuable technical assistance.

\section{REFERENCES}

1. K. Thaipong, U. Boonprakob, K. Crosby, L. CisnerosZevallos and D. H. Byrne, J. Food Comp. Anal., 2006, 19, 669-675
2. E. A. Shalaby and S. M. Shanab, Pharm. Pharmacol., 2013, 7, 528-539.

3. A. Parsa and S. A. Salout, J. Electroanal. Chem., 2016, 760, 113-118.

4. I. F. Benzie and J. J. Strain, Anal. Biochem., 1996, 239, 70-76.

5. A. Kaushik, C. Jijta, J. J. Kaushik, R. Zeray, A. Ambesajir and L. Beyene, Indian J. Nat. Prod. Resour., 2012.

6. M. N. Alam, N. J. Bristi and M. Rafiquzzaman, Saudi Pharm. J., 2013, 21, 143-152.

7. M. Antolovich, P. D. Prenzler, E. Patsalides, S. McDonald and K. Robards, Analyst., 2002, 127, 183-198.

8. J. Stejskal, M. Trchová, I. A. Ananieva, J. Janca, J. Prokes, S. Fedorova and I. Sapurina, Synth. Met., 2004, 146, 29-36.

9. A. Parsa and S. Ab Ghani, J. Electrochem. Soc., 2009, 156, E105-E111.

10. C. Jérôme, D. E. Labaye and R. Jérôme, Synth. Met., 2004, 142, 207-216.

11. A. Parsa and S. Ab Ghani, Polymer, 2008, 49, 3702-3708.

12. H. Karami, S. Jafari and F. Goli, Int. J. Electrochem. Sci., 2016, 11, 3056-3073.

13. C. R. Martin, Acc. Chem. Research, 1995, 28, 61-68.

14. A. Prasannan, N. Somanathan, P.-D. Hong and W.-T. Chuang, Mater. Chem. Phys., 2009, 116, 406-414.

15. Y. Lu, G. Shi, C. Li and Y. Liang, J. Appl. Polym. Sci., 1998, 70, 2169-2172.

16. T. Li, Y. Zhou, Z. Dou, L. Ding, S. Dong, N. Liu and Z. Qin, Electrochim. Acta, 2017, 243, 228-238.

17. B. Sar1 and M. Talu, Synth. Met., 1998, 94, 221-227.

18. V. ChinhTran, S. Sahoo, J. Hwang, V. Q. Nguyen and J.J. Shim, J. Electroanal. Chem., 2018.

19. S. Weng, J. Zhou and Z. Lin, Synth. Met., 2010, 160, 1136-1142.

20. M. Kamran, H. Ullah, A. S. Anwar-ul-Haq, S. Bilal, A. A. Tahir and K. Ayub, Polym., 2015, 72, 30-39.

21. A. Gohari, H. Hajimehdipoor, S. Saeidnia, Y. Ajani and A. Hadjiakhoondi, J. Med Plant., 2011, 1, 54-60.

22. P. Rodríguez-Bonilla, F. Gandía-Herrero, A. Matencio, F. García-Carmona and J. M. López-Nicolás, Food Anal. Method., 2017, 1-7.

23. Y. Ustundag, K. Huysal, S. Kahvecioglu, H. Demirci, S. Yavuz, M. Sambel and D. Unal, EuRJ., 2016, 2, 126. 
